\title{
BMJ Open Acute myocardial infarction or acute myocarditis? Discharge registry-based study of likelihood and associated features in hospitalised patients
}

\author{
Ville Kytö, ${ }^{1,2,3}$ Jussi Sipilä,, ${ }^{4,5}$ Päivi Rautava ${ }^{6,7}$
}

To cite: Kytö V, Sipilä J, Rautava P. Acute myocardial infarction or acute myocarditis? Discharge registry-based study of likelihood and associated features in hospitalised patients. BMJ Open 2015;5: e007555. doi:10.1136/ bmjopen-2014-007555

- Prepublication history for this paper is available online. To view these files please visit the journal online (http://dx.doi.org/10.1136/ bmjopen-2014-007555).

Received 28 December 2014 Revised 16 March 2015 Accepted 20 March 2015

CrossMark

For numbered affiliations see end of article.

Correspondence to

Dr Ville Kytö;

ville.kyto@utu.fi

\section{ABSTRACT}

Objective: To evaluate the likelihood of and patient features associated with acute myocardial infarction (AMI) versus acute myocarditis in different population segments.

Design: Nationwide, multihospital observational retrospective registry study of 9.6 years in Finland. Participants: All consecutive patients aged $\geq 18$ years hospitalised with a primary diagnosis of AMI $(\mathrm{n}=89399)$ or acute myocarditis $(\mathrm{n}=2131)$ in 22 hospitals with a coronary catheterisation laboratory.

Primary outcome measures: Likelihood of AMI versus acute myocarditis and associated patient features.

Results: Men were over-represented in patients with AMI (59.8\%) and in patients with acute myocarditis (76.1\%). Age distributions of AMI and acute myocarditis were opposite as a majority of patients with myocarditis were aged 18-29 years, while the number of patients with AMI increased gradually up to 80 years of age. Patients aged 18-29 years were more likely to have acute myocarditis as the cause of hospitalisation (relative risk (RR) $=11.4 ; 95 \% \mathrm{Cl} 7.6$ to 16.1 for myocarditis, $p<0.0001$ ), but after 30 years of age the likelihood of infarction was higher with exponentially increasing RR for AMI. In youngest patients (18-29 years), the likelihood of AMI was higher in women, but men had higher odds for AMI after 40 years of age. Overall, men had OR of 1.97 (95\% Cl 1.74 to $2.23, p<0.0001$ ) for AMI versus myocarditis when compared with women. Hypercholesterolaemia, chronic coronary artery disease, diabetes and hypertension predicted AMI in multivariate analysis. Odds for myocarditis were significantly higher if the patient had an otolaryngeal infection (OR 18.13; $95 \% \mathrm{Cl} 8.96$ to $36.67, \mathrm{p}<0.0001$ ).

Conclusions: Acute myocarditis is more common than AMI in hospitalised patients aged 18-29 years, but the risk of AMI increases exponentially thereafter. Hypercholesterolaemia, diabetes and hypertension predict AMI regardless of age and gender.

\section{INTRODUCTION}

Acute myocardial infarction (AMI) and acute myocarditis have commonly similar clinical

\section{Strengths and limitations of this study}

- Characterises the likelihood of acute myocardial infarction (AMI) versus acute myocarditis in different segments of the general population.

- Large-scale nationwide study using obligatory and controlled registry data from hospitals with a coronary catherisation laboratory.

- Diagnoses of AMI and acute myocarditis were carried out by treating physicians.

presentations. ${ }^{1}$ As changes in $\mathrm{ECG}^{2}$ and troponin levels ${ }^{3}$ are also alike, differential diagnosis may be very challenging and frequently requires invasive assessment of coronary arteries. ${ }^{4}$ Culprit-free coronary angiography is found in $5-13 \%$ of patients with suspected $\mathrm{AMI}^{5}{ }^{5}$ and a majority of patients with culprit-free angiography actually have myocarditis. ${ }^{6}$ Although epidemiology of AMI has been described in large patient series, ${ }^{7-12}$ epidemiology of acute myocarditis is less well established. ${ }^{13}$ Furthermore, there are currently no large-scale studies reporting on the risk of AMI versus acute myocarditis in different population segments. Therefore, we sought to estimate the likelihood of AMI versus acute myocarditis and associated patient features at the population level.

\section{METHODS}

\section{Study patients and data collection}

We included all consecutive patients aged $\geq 18$ years who were admitted to a participating hospital between 29 April 2000 and 29 November 2009 with an AMI (ICD-10 code I21.x) or an acute myocarditis (ICD-10 code I40.x or I01.2) as the primary discharge diagnosis. Diagnoses were made by treating physicians. Confirmatory data of performed diagnostic tests were not available. Data were collected from all Finnish hospitals equipped with a coronary catheterisation laboratory 
$(\mathrm{n}=22)$ by using the Finnish National Institute for Health and Welfare maintained Finnish Hospital Discharge Register (FHDR) database. The study was approved by the National Institute for Health and Welfare (permission no THL/1576/5.05.00/2010).

\section{Statistical analysis}

Categorical variables are presented as counts or percentages with 95\% CIs (95\% CI) as appropriate. Scale variables are presented as mean $\pm \mathrm{SD}$. Count variables were analysed using negative binomial regression. Differences in dichotomous variables were analysed using logistic regression analysis with Firths correction and adjusted for study year. Results of regression analyses are given as OR or relative risk (RR) as appropriate. Multivariate analysis of patient features associated with the likelihood of myocardial infarction/myocarditis included features associated at $\mathrm{p}<0.05$ in univariate analysis. CIs were calculated assuming Poisson distribution. The $p$ values $<0.05$ were considered statistically significant. Statistical analyses were performed with SAS system V.9.3 (SAS Institute, Cary, North Carolina, USA).

\section{RESULTS}

\section{Patient characteristics}

During the study period, AMI resulted in 89399 admissions, and acute myocarditis numbered 2131. Men were over-represented both in patients with AMI $(59.8 \%)$ and in patients with acute myocarditis $(76.1 \%)$. Patients with AMI were significantly older than those with myocarditis $(71.2 \pm 12.7$ vs $38.0 \pm 16.9$ years, $\mathrm{p}<0.0001)$. Diabetes, hypertension, hypercholesterolaemia, chronic pulmonary disease, neurovascular disease, malignancy and renal insufficiency, in addition to atrial fibrillation, heart failure and known atherosclerotic disease of coronary, cerebral or peripheral arteries were more common in patients hospitalised for AMI (table 1). By contrast, infections of the otolaryngeal tract and inflammatory bowel disease were more common in patients with myocarditis (table 1). The average duration of admission for AMI lasted, $6.9 \pm 5.7$ days, while admission due to acute myocarditis was shorter $(5.3 \pm 4.3$ days, $\mathrm{p}<0.0001)$. Of patients with AMI, $0.03 \%$ had a co-diagnosis of myocarditis, while $0.37 \%$ of patients with myocarditis were also diagnosed with AMI.

\section{Age distribution}

Age distribution of patients with AMI and acute myocarditis were opposite (figure 1). The majority of patients with myocarditis were aged 18-29 years, after which the number of patients decreased (figure 1A). The number of patients with AMI increased gradually up to 80 years of age (figure 1B). Patients aged 18-29 years were more likely to have acute myocarditis as the cause of hospitalisation ( $\mathrm{RR}=11.4 ; 95 \%$ CI 7.6 to 16.1 for myocarditis, $\mathrm{p}<0.0001$ ), but after 30 years of age the likelihood of infarction was higher with exponentially increasing RR

Table 1 Co-diagnoses of patients hospitalised for acute myocardial infarction or myocarditis and differences between patients in univariate analyses

\begin{tabular}{|c|c|c|c|c|}
\hline \multirow[b]{3}{*}{ Co-diagnosis } & \multicolumn{2}{|l|}{ Prevalence } & \multirow{2}{*}{\multicolumn{2}{|c|}{$\begin{array}{l}\text { Difference } \\
\text { Univariate analysis (infarction } \\
\text { vs myocarditis) }\end{array}$}} \\
\hline & \multirow{2}{*}{$\begin{array}{l}\text { Acute myocardial } \\
\text { infarction } \\
\%(95 \% \mathrm{Cl})\end{array}$} & \multirow{2}{*}{$\begin{array}{l}\text { Acute myocarditis } \\
\%(95 \% \mathrm{Cl})\end{array}$} & & \\
\hline & & & OR (95\% Cl) & p Value \\
\hline Chronic coronary artery disease & $15.36(15.10$ to 15.62$)$ & 1.55 (1.07 to 2.17$)$ & $11.52(8.19$ to 16.21$)$ & $<0.0001$ \\
\hline Hypertension & $13.12(12.89$ to 13.36$)$ & 4.04 (3.23 to 4.98$)$ & 3.59 (2.89 to 4.45$)$ & $<0.0001$ \\
\hline Heart failure & 11.57 (11.35 to 11.79$)$ & 2.25 (1.66 to 2.99$)$ & 5.63 (4.23 to 7.49$)$ & $<0.0001$ \\
\hline Diabetes & 7.84 (7.66 to 8.03$)$ & $1.13(0.72$ to 1.68$)$ & $7.32(4.91$ to 10.90$)$ & $<0.0001$ \\
\hline Atrial fibrillation & $6.64(6.5$ to 6.8$)$ & 1.55 (1.07 to 2.17$)$ & 4.44 (3.16 to 6.25$)$ & $<0.0001$ \\
\hline Hypercholesterolaemia & $6.52(6.35$ to 6.69$)$ & $1.03(0.65$ to 1.56$)$ & 6.51 (4.30 to 9.86$)$ & $<0.0001$ \\
\hline Pneumonia & 3.12 (3.00 to 3.23$)$ & 3.33 (2.60 to 4.20$)$ & $0.92(0.73$ to 1.17$)$ & 0.50 \\
\hline Chronic pulmonary disease & 2.18 (2.08 to 2.28$)$ & $1.27(0.83$ to 1.84$)$ & 1.70 (1.17 to 2.49$)$ & 0.0059 \\
\hline Neurovascular disease & 1.34 (1.27 to 1.42$)$ & $0.14(0.03$ to 0.41$)$ & 8.32 (2.91 to 23.77$)$ & $<0.0001$ \\
\hline Ventricular arrhythmia or resuscitation & $1.13(1.07$ to 1.21$)$ & 0.99 (0.61 to 1.51$)$ & $1.13(0.73$ to 1.73$)$ & 0.59 \\
\hline Malignancy & $1.04(0.98$ to 1.11$)$ & $0.42(0.19$ to 0.80$)$ & 2.35 (1.24 to 4.46$)$ & 0.0089 \\
\hline Peripheral artery disease & $0.86(0.8$ to 0.9$)$ & $0.05(0.01$ to 0.26$)$ & 12.39 (2.50 to 61.46$)$ & 0.0021 \\
\hline Renal insufficiency & $0.83(0.77$ to 0.89$)$ & 0.09 (0.01 to 0.34$)$ & 4.15 (2.07 to 24.72$)$ & 0.0019 \\
\hline II or III degree AV block & $0.59(0.54$ to 0.64$)$ & 0.89 (0.54 to 1.39$)$ & $0.65(0.41$ to 1.02$)$ & 0.060 \\
\hline Rheumatoid arthritis & $0.44(0.39$ to 0.48$)$ & $0.52(0.26$ to 0.92$)$ & $0.81(0.45$ to 1.46$)$ & 0.50 \\
\hline Gastroenteral infection & $0.38(0.34$ to 0.43$)$ & $0.38(0.16$ to 0.74$)$ & $0.96(0.48$ to 1.89$)$ & 0.89 \\
\hline Septicaemia & $0.36(0.32$ to 0.40$)$ & 0.23 (0.08 to 0.55$)$ & 1.39 (0.60 to 3.23$)$ & 0.44 \\
\hline Systemic connective tissue disease & $0.18(0.16$ to 0.21$)$ & 0.23 (0.08 to 0.55$)$ & 0.70 (0.30 to 1.64$)$ & 0.41 \\
\hline Otolaryngeal infection & $0.12(0.10$ to 0.15$)$ & 2.49 (1.86 to 3.25$)$ & 0.05 (0.04 to 0.07$)$ & $<0.0001$ \\
\hline Liver dysfunction & $0.11(0.09$ to 0.13$)$ & $0.14(0.03$ to 0.41$)$ & $0.66(0.23$ to 1.93$)$ & 0.50 \\
\hline Inflammatory bowel disease & $0.10(0.08$ to 0.12$)$ & $0.38(0.16$ to 0.74$)$ & 0.26 (0.13 to 0.52$)$ & 0.0002 \\
\hline
\end{tabular}


for AMI (figure 2). In the total study population, the age-adjusted and gender-adjusted RR for AMI was 60.4 (95\% CI 39.3 to $92.8, \mathrm{p}<0.0001$ ).

\section{Patient features associated with AMI}

The likelihood of AMI increased significantly with increasing age. In the total population, comorbidity adjusted OR for AMI was 4.69 (95\% CI 4.48 to 4.91, $\mathrm{p}<0.0001)$ per 10 -year increase in age. The gender-based difference in likelihood of AMI compared with myocarditis varied significantly by age (figure 3 ). In the youngest patients (18-29 years), the likelihood of AMI was higher in women, but men had higher odds for AMI after 40 years of age. Overall, men had significantly higher odds for AMI versus myocarditis when compared with women (OR 1.97; 95\% CI 1.74 to $2.23, \mathrm{p}<0.0001$ ). Comorbidities predicting AMI in multivariate analysis included hypercholesterolaemia, chronic coronary artery disease, diabetes and hypertension (table 2). The odds for myocarditis were significantly higher if the patient had an otolaryngeal infection (OR 18.13; 95\% CI 8.96 to $36.67, \mathrm{p}<0.0001)$. In addition, atrial fibrillation and
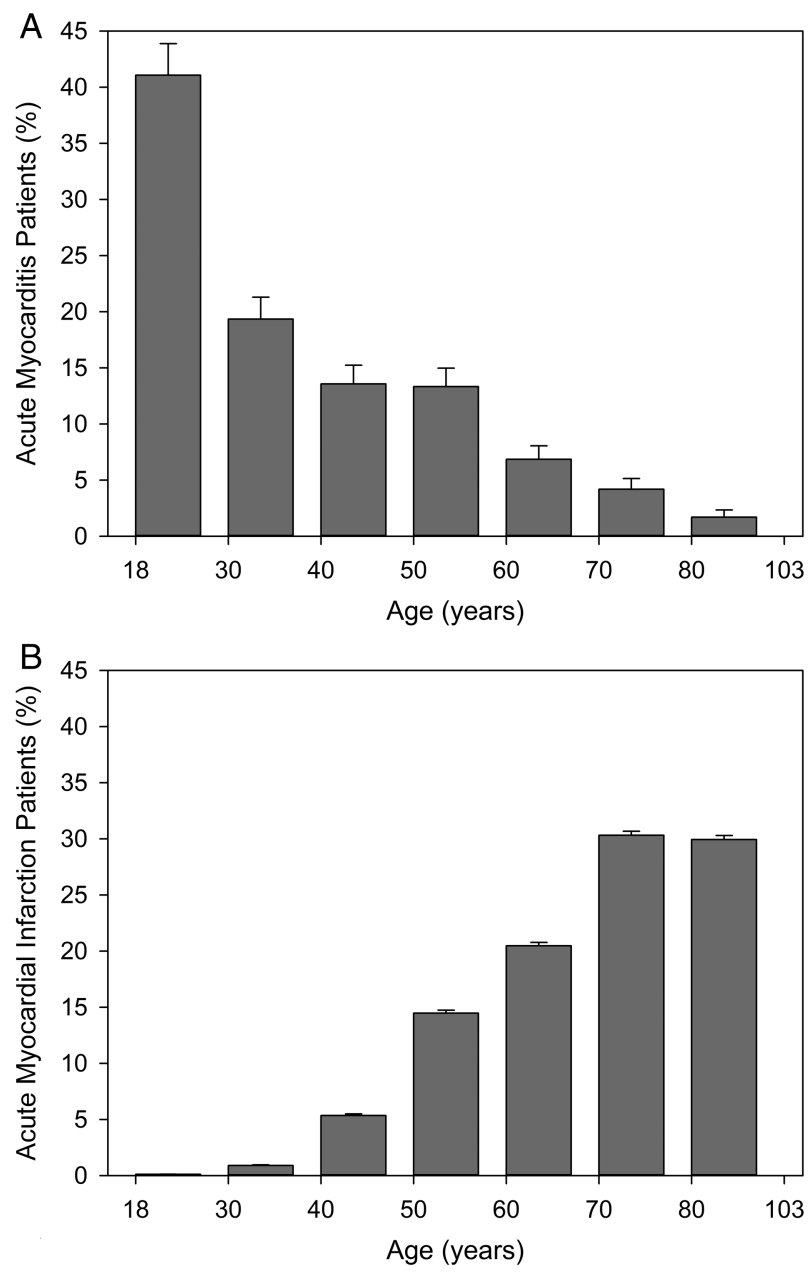

Figure 1 Age distribution of patients with acute myocarditis (A) and acute myocardial infarction (B). Error bars represent upper $95 \%$ Cls.

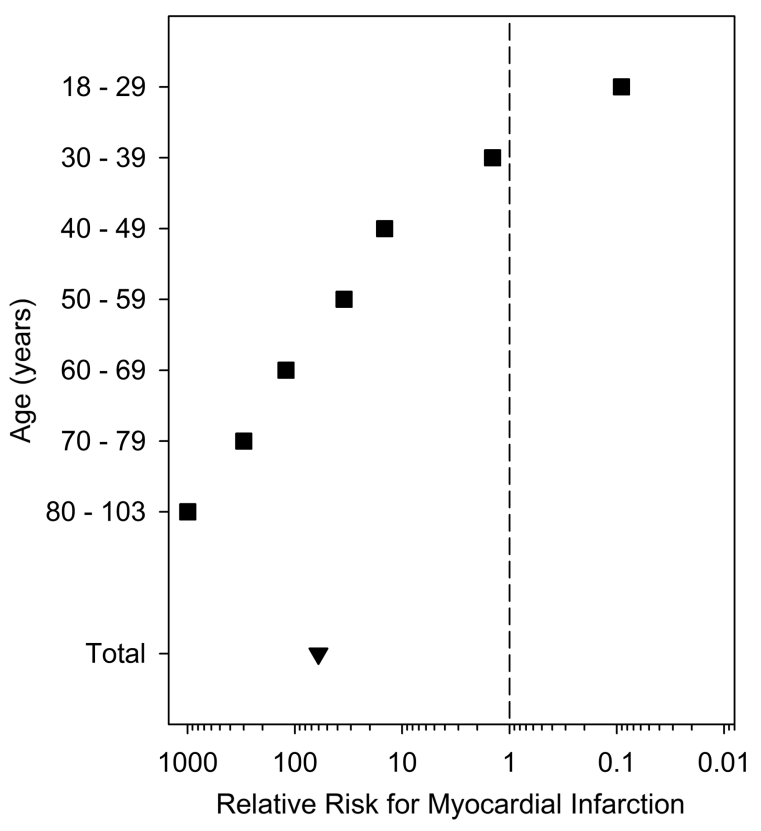

Figure 2 Age-specific relative risk for acute myocardial infarction in patients hospitalised for acute myocardial infarction or acute myocarditis. Note the logarithmic scale of the $x$ axis.

chronic pulmonary disease were more common among patients with acute myocarditis when adjusted for other comorbidities and patient features (table 2).

\section{DISCUSSION}

This multicentre study describes the likelihood and predictors of AMI versus acute myocarditis in hospitalised

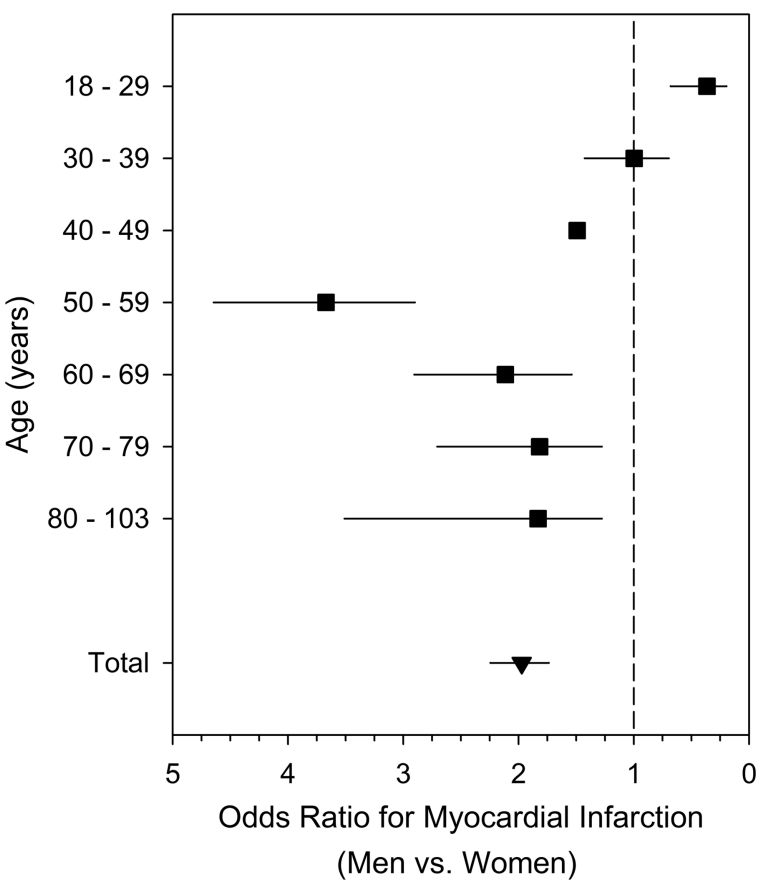

Figure 3 Gender differences in odds for acute myocardial infarction versus acute myocarditis in different age groups. Error bars represent 95\% Cls. 
Table 2 Predictors of acute myocardial infarction in multivariate analysis

\begin{tabular}{|c|c|c|}
\hline \multirow[b]{2}{*}{ Patient characteristic } & \multicolumn{2}{|c|}{$\begin{array}{l}\text { Multivariate analysis } \\
\text { (infarction vs myocarditis) }\end{array}$} \\
\hline & OR (95\% Cl) & p Value \\
\hline $\begin{array}{l}\text { Age (per 10-year } \\
\text { increase) }\end{array}$ & 4.69 (4.48 to 4.91$)$ & $<0.0001$ \\
\hline Male sex & 1.97 (1.74 to 2.24$)$ & $<0.0001$ \\
\hline Hypercholesterolaemia & 8.68 (5.66 to 13.33$)$ & $<0.0001$ \\
\hline $\begin{array}{l}\text { Chronic coronary artery } \\
\text { disease }\end{array}$ & 6.10 (4.28 to 8.69$)$ & $<0.0001$ \\
\hline Diabetes & 4.85 (3.18 to 7.42$)$ & $<0.0001$ \\
\hline Hypertension & $1.42(1.12$ to 1.80$)$ & 0.0035 \\
\hline $\begin{array}{l}\text { Chronic pulmonary } \\
\text { disease }\end{array}$ & 0.61 (0.38 to 0.98$)$ & 0.043 \\
\hline Atrial fibrillation & 0.55 (0.38 to 0.80$)$ & 0.0017 \\
\hline Otolaryngeal infection & 0.06 (0.03 to 0.11$)$ & $<0.0001$ \\
\hline Neurovascular disease & 2.77 (0.89 to 8.61$)$ & 0.078 \\
\hline Peripheral artery disease & $2.70(0.48$ to 15.25$)$ & 0.26 \\
\hline Renal insufficiency & $2.44(0.66$ to 9.04$)$ & 0.18 \\
\hline Heart failure & $1.28(0.93$ to 1.76$)$ & 0.12 \\
\hline $\begin{array}{l}\text { Inflammatory bowel } \\
\text { disease }\end{array}$ & $0.62(0.19$ to 1.96$)$ & 0.41 \\
\hline Malignancy & 0.56 (0.28 to 1.14$)$ & 0.11 \\
\hline
\end{tabular}

patients at the population level. Differential diagnosis between AMI and acute myocarditis is critical, as timely invasive treatment significantly improves outcomes in AMI. ${ }^{14}{ }^{15}$ As clinical, ECG and biomarker presentations of AMI and acute myocarditis may be highly similar, ${ }^{2-4}$ the assumed probability of AMI or myocarditis is likely to act as a significant gatekeeper for coronary angiography and treatment. Although epidemiology of AMI has been described previously in large patient series, ${ }^{7-9} 1216$ studies on epidemiology of myocarditis are scarce, ${ }^{13}$ and there are no estimations available for likelihood of AMI versus acute myocarditis in different population segments.

We found the youngest (18-29 years) patients to have an 11-fold risk for myocarditis compared with AMI, but AMI was more common in the population older than 30 years. This compares to a previous study of emergency department patients with chest pain that found $33 \%$ of patients aged 18-40 years positive for troponin to have AMI while myocarditis was present in $59 \% .{ }^{17}$ Age distributions of patients with AMI and acute myocarditis were opposite in our data, resulting in the exponentially increasing likelihood of AMI with increasing age. $\mathrm{AMI}^{9}{ }^{18}$ and myocarditis ${ }^{13}$ are more common in men than in women, but the current study is, to the best of our knowledge, the first to report on gender differences in the likelihood of AMI versus acute myocarditis. The gender bias in the occurrence of myocarditis is highest in young adults. ${ }^{13}$ Accordingly, we found women aged 18-29 years to have higher odds for AMI than equally aged men. High incidence of acute myocarditis in young men is most likely associated with effects of testosterone, ${ }^{19}$ as testosterone treatment aggravates myocarditis ${ }^{20}$ in experimental myocarditis, while gonadectomy reduces cardiac inflammation. ${ }^{21}$ In the population aged over 40 years, the odds for AMI were, however, higher in men, and in the total study population men had twofold odds for AMI when compared with women.

Classical risk factors for coronary artery disease, hypertension, hypercholesterolaemia and diabetes ${ }^{22} 23$ predicted AMI rather than acute myocarditis in our data regardless of age and gender. Although our data do not allow reporting directly on patients' smoking status, the association of chronic pulmonary disease with AMI is most likely to reflect the effects of smoking. Coronary angiography should also be considered in young patients with troponin-positive chest pain, especially if risk factors are present. ${ }^{4}$ However, of patients with suspected AMI, $5-13 \%$ have no detectable culprit lesion, ${ }^{54-28}$ and these findings are consistent regardless of whether ST-segment elevation AMI (STEMI) ${ }^{27-30}$ or non-ST-segment elevation AMI (NSTEMI) ${ }^{24-26}$ is suspected. Of culprit-free patients, myocarditis is detectable by cardiac MRI (CMR) ${ }^{31-34}$ or scintigraphy ${ }^{6}$ in $50-78 \%$. Since there are no effective special treatments available for common uncomplicated acute viral myocarditis, usage of imaging studies beyond echocardiography in suspected acute myocarditis is controversial and currently uncommon in clinical reality. CMR is an evolving entity for detection of myocarditis. ${ }^{35} 36$ It is, however, not feasible as the first-line diagnostic modality in suspected STEMI when diagnosis of AMI must be made immediately in order to enable efficient reperfusion therapy. Routine use of CMR in patients with suspected NSTEMI is currently under investigation. ${ }^{37}$ Novel, clinically easy and rapidly applicable methods to differentiate between AMI and acute myocarditis are thus warranted.

The major limitation of our study is the retrospective nature of observational discharge registry data. The diagnoses were made by the treating physician and the nature of data does not allow us to report on used diagnostic tests or patient's risk-factor behaviour such as smoking. To optimise the balance between representation of all-comer real-life patients and diagnostic accuracy, only patients admitted to hospitals with a coronary catheterisation laboratory were included. Study data were collected from the FHDR registry that has proved to be a valuable source of information on acute cardiovascular disorders ${ }^{38}$ and has been previously validated. ${ }^{39}{ }^{40}$ Diagnostic inaccuracies are, however, possible, especially in recognition of comorbidities. ${ }^{23}$ Confirmatory diagnosis of myocarditis requires endomyocardial biopsy, which is rarely indicated in a clinical setting of acute myocarditis. ${ }^{1}$ If biopsy is not obtained, myocarditis may be classified as clinically suspected ${ }^{4}$ or probable $^{41}$ if cardiac symptoms are associated with changes in troponin, ECG or cardiac imaging studies in the absence of an acute coronary syndrome or other reasons. The majority of patients with acute myocarditis in our study probably belong to this category. 
It is a common misbelief that acute myocarditis presents only with ST-segment elevations in ECG. Recent studies of CMR-detected acute/viral myocarditis have found $34-57 \%$ of patients to have ST-segment elevations, while ECG was normal at the presentation in approximately $30 \%$ of patients. ${ }^{42}{ }^{43}$ Depressions of ST-segment are reported in $6-18 \%$ of patients. ${ }^{6}{ }^{42}$ Thus, the need for differentiation between myocarditis and AMI includes all patients with suspected AMI regardless of ECG presentation.

In conclusion, acute myocarditis is more common than AMI in hospitalised patients aged 18-29 years, but the risk of AMI increases exponentially thereafter. Men aged $\geq 40$ years are more likely to have AMI than myocarditis when compared with women. Hypercholesterolaemia, diabetes and hypertension predict AMI regardless of age and gender.

\author{
Author affiliations \\ ${ }^{1}$ Heart Center, Turku University Hospital, Turku, Finland \\ ${ }^{2}$ PET Center, University of Turku, Turku, Finland \\ ${ }^{3}$ Department of Medicine, University of Turku, Turku, Finland \\ ${ }^{4}$ Division of Clinical Neurosciences, Department of Neurology, Turku \\ University Hospital, Turku, Finland \\ ${ }^{5}$ Department of Neurology, University of Turku, Turku, Finland \\ ${ }^{6}$ Clinical Research Center, Turku University Hospital, Turku, Finland \\ ${ }^{7}$ Department of Public Health, University of Turku, Turku, Finland
}

Contributors VK, JS and PR designed the study. VK and JS collected the data. VK conducted the analyses, all contributed to the interpretation of the results and VK drafted the manuscript. All authors accepted the final version of the manuscript.

Funding This study was supported by the grants of the Clinical Research Foundation of the Turku University Hospital and the Finnish Cardiac Society.

Competing interests None declared.

Ethics approval Finnish National Institute for Health and Welfare.

Provenance and peer review Not commissioned; externally peer reviewed.

Data sharing statement No additional data are available.

Open Access This is an Open Access article distributed in accordance with the Creative Commons Attribution Non Commercial (CC BY-NC 4.0) license, which permits others to distribute, remix, adapt, build upon this work noncommercially, and license their derivative works on different terms, provided the original work is properly cited and the use is non-commercial. See: http:// creativecommons.org/licenses/by-nc/4.0/

\section{REFERENCES}

1. Kindermann I, Barth C, Mahfoud F, et al. Update on myocarditis. J Am Coll Cardiol 2012;59:779-92.

2. Porela $P$, Kytö V, Nikus $K$, et al. PR depression is useful in the differential diagnosis of myopericarditis and ST elevation myocardial infarction. Ann Noninvasive Electrocardiol 2012;17:141-5.

3. Agewall S, Giannitsis E, Jernberg T, et al. Troponin elevation in coronary vs. non-coronary disease. Eur Heart J 2011;32:404-11.

4. Caforio AL, Pankuweit S, Arbustini E, et al, European Society of Cardiology Working Group on Myocardial and Pericardial Diseases. Current state of knowledge on aetiology, diagnosis, management, and therapy of myocarditis: a position statement of the European Society of Cardiology Working Group on Myocardial and Pericardial Diseases. Eur Heart J 2013;34:2636-48.

5. Gallagher S, Jones DA, Anand V, et al. Diagnosis and management of patients with acute cardiac symptoms, troponin elevation and culprit-free angiograms. Heart 2012;98:974-81.
6. Sarda L, Colin P, Boccara F, et al. Myocarditis in patients with clinical presentation of myocardial infarction and normal coronary angiograms. J Am Coll Cardiol 2001;37:786-92.

7. Rosamond WD, Chambless LE, Heiss G, et al. Twenty-two-year trends in incidence of myocardial infarction, coronary heart disease mortality, and case fatality in 4 US communities, 1987-2008. Circulation 2012;125:1848-57.

8. Yeh RW, Sidney S, Chandra M, et al. Population trends in the incidence and outcomes of acute myocardial infarction. $N$ Engl $J$ Med 2010;362:2155-65.

9. Go AS, Mozaffarian D, Roger VL, et al, American Heart Association Statistics Committee and Stroke Statistics Subcommittee. Heart disease and stroke statistics-2014 update: a report from the American Heart Association. Circulation 2014;129:e28-e292.

10. Coppieters $\mathrm{Y}$, Collart $\mathrm{P}$, Leveque A. Gender differences in acute myocardial infarction, twenty-five years registration. Int $J$ Cardiol 2012;160:127-32.

11. Laks $\mathrm{T}$, Joeste $\mathrm{E}$, Pullisaar $\mathrm{O}$, et al. Trends in incidence, attack rate, and mortality of acute myocardial infarction in Estonia: the Tallinn AMI Registry 1991-2005. Ann Med 2013;45:107-11.

12. Radovanovic D, Erne P. AMIS Plus: Swiss registry of acute coronary syndrome. Heart 2010;96:917-21.

13. Kytö V, Sipilä J, Rautava P. The effects of gender and age on occurrence of clinically suspected myocarditis in adulthood. Heart 2013;99:1681-4.

14. Steg PG, James SK, Atar D, et al, Task Force on the management of ST-segment elevation acute myocardial infarction of the ESC, ESC Guidelines for the management of acute myocardial infarction in patients presenting with ST-segment elevation. Eur Heart $J$ 2012;33:2569-619.

15. Hamm CW, Bassand JP, Agewall S, et al. ESC Guidelines for the management of acute coronary syndromes in patients presenting without persistent ST-segment elevation: the Task Force for the management of acute coronary syndromes (ACS) in patients presenting without persistent ST-segment elevation of the European Society of Cardiology (ESC). Eur Heart J 2011;32:2999-3054.

16. Movahed MR, Ramaraj R, Hashemzadeh M, et al. Rate of acute ST-elevation myocardial infarction in the United States from 1988 to 2004 (from the Nationwide Inpatient Sample). Am J Cardiol 2009;104:5-8.

17. Pellaton C, Monney P, Ludman AJ, et al. Clinical features of myocardial infarction and myocarditis in young adults: a retrospective study. BMJ Open 2012;2:e001571.

18. Radovanovic D, Erne $P$, Urban $P$, et al. Gender differences in management and outcomes in patients with acute coronary syndromes: results on 20,290 patients from the AMIS Plus Registry. Heart 2007;93:1369-75.

19. Fairweather D, Cooper LT Jr, Blauwet LA. Sex and gender differences in myocarditis and dilated cardiomyopathy. Curr Probl Cardiol 2013;38:7-46.

20. Lyden DC, Olszewski J, Feran M, et al. Coxsackievirus B-3-induced myocarditis. Effect of sex steroids on viremia and infectivity of cardiocytes. Am J Pathol 1987;126:432-8.

21. Frisancho-Kiss S, Coronado MJ, Frisancho JA, et al. Gonadectomy of male BALB/c mice increases Tim-3(+) alternatively activated M2 macrophages, Tim-3(+) T cells, Th2 cells and Treg in the heart during acute coxsackievirus-induced myocarditis. Brain Behav Immun 2009;23:649-57.

22. Goff DC Jr, Lloyd-Jones DM, Bennett G, et al, American College of Cardiology/American Heart Association Task Force on Practice Guidelines. 2013 ACC/AHA guideline on the assessment of cardiovascular risk: a report of the American College of Cardiology/ American Heart Association Task Force on Practice Guidelines. Circulation 2014;129:S49-73.

23. Radovanovic D, Seifert B, Urban P, et al. Validity of Charlson Comorbidity Index in patients hospitalised with acute coronary syndrome. Insights from the nationwide AMIS Plus registry 2002-2012. Heart 2014;100:288-94.

24. Patel MR, Chen AY, Peterson ED, et al. Prevalence, predictors, and outcomes of patients with non-ST-segment elevation myocardial infarction and insignificant coronary artery disease: results from the Can Rapid risk stratification of Unstable angina patients Suppress ADverse outcomes with Early implementation of the ACC/AHA Guidelines (CRUSADE) initiative. Am Heart $J$ 2006;152:641-7.

25. Cortell A, Sanchis J, Bodi V, et al. Non-ST-elevation acute myocardial infarction with normal coronary arteries: predictors and prognosis. Rev Esp Cardiol 2009;62:1260-6.

26. Kang WY, Jeong MH, Ahn YK, et al. Are patients with angiographically near-normal coronary arteries who present as acute myocardial infarction actually safe? Int J Cardiol 2011;146:207-12. 
27. Andersen HR, Nielsen TT, Rasmussen K, et al. A comparison of coronary angioplasty with fibrinolytic therapy in acute myocardial infarction. N Engl J Med 2003;349:733-42.

28. Bonnefoy $\mathrm{E}$, Lapostolle $\mathrm{F}$, Leizorovicz A, et al. Primary angioplasty versus prehospital fibrinolysis in acute myocardial infarction: a randomised study. Lancet 2002;360:825-9.

29. Prasad SB, Richards DA, Sadick N, et al. Clinical and electrocardiographic correlates of normal coronary angiography in patients referred for primary percutaneous coronary intervention. Am J Cardiol 2008;102:155-9.

30. Larson DM, Menssen KM, Sharkey SW, et al. "False-positive" cardiac catheterization laboratory activation among patients with suspected ST-segment elevation myocardial infarction. JAMA 2007;298:2754-60

31. Baccouche $\mathrm{H}$, Mahrholdt $\mathrm{H}$, Meinhardt $\mathrm{G}$, et al. Diagnostic synergy of non-invasive cardiovascular magnetic resonance and invasive endomyocardial biopsy in troponin-positive patients without coronary artery disease. Eur Heart J 2009;30:2869-79.

32. Monney PA, Sekhri N, Burchell T, et al. Acute myocarditis presenting as acute coronary syndrome: role of early cardiac magnetic resonance in its diagnosis. Heart 2011;97:1312-18.

33. Assomull RG, Lyne JC, Keenan N, et al. The role of cardiovascular magnetic resonance in patients presenting with chest pain, raised troponin, and unobstructed coronary arteries. Eur Heart $J$ 2007;28:1242-9.

34. Leurent G, Langella B, Fougerou C, et al. Diagnostic contributions of cardiac magnetic resonance imaging in patients presenting with elevated troponin, acute chest pain syndrome and unobstructed coronary arteries. Arch Cardiovasc Dis 2011;104:161-70.
35. Friedrich MG, Sechtem U, Schulz-Menger J, et al. Cardiovascular magnetic resonance in myocarditis: a JACC White Paper. J Am Coll Cardiol 2009;53:1475-87.

36. Francone M, Chimenti C, Galea N, et al. CMR sensitivity varies with clinical presentation and extent of cell necrosis in biopsy-proven acute myocarditis. JACC Cardiovasc Imaging 2014;7:254-63.

37. Smulders MW, Kietselaer BL, Das M, et al. The role of cardiovascular magnetic resonance imaging and computed tomography angiography in suspected non-ST-elevation myocardial infarction patients: design and rationale of the CARdiovascular Magnetic rEsoNance imaging and computed Tomography Angiography (CARMENTA) trial. Am Heart J 2013;166:968-75.

38. Kytö V, Sipilä J, Rautava P. Association of age and gender with risk for non-ST-elevation myocardial infarction. Eur J Prev Cardiol 2014. doi:10.1177/2047487314539434 [In press].

39. Sund R. Quality of the Finnish Hospital Discharge Register: a systematic review. Scand J Public Health 2012;40:505-15.

40. Pajunen $\mathrm{P}$, Koukkunen $\mathrm{H}$, Ketonen $\mathrm{M}$, et al. The validity of the Finnish Hospital Discharge Register and Causes of Death Register data on coronary heart disease. Eur J Cardiovasc Prev Rehabil 2005;12:132-7.

41. Cooper LT, Knowlton KU. Myocarditis. In: Mann DL, Zipes DP, Libby $\mathrm{P}$, et al, eds. Braunwald's heart disease a textbook of cardiovascular medicine. 10th edn. Philadelphia, PA: Elsevier, 2014:1589-602.

42. Deluigi CC, Ong P, Hill S, et al. ECG findings in comparison to cardiovascular MR imaging in viral myocarditis. Int $J$ Cardiol 2013;165:100-6.

43. Di Bella G, Florian A, Oreto L, et al. Electrocardiographic findings and myocardial damage in acute myocarditis detected by cardiac magnetic resonance. Clin Res Cardiol 2012;101:617-24. 